\title{
FORMAÇÃO INICIAL DE PROFESSORES. UM ROTEIRO PARA O ANO DE ESTÁGIO ${ }^{1}$
}

\author{
Maria Goretti Valente ${ }^{2}$ \\ José Afonso Baptista ${ }^{3}$
}

\begin{abstract}
Resumo: Os professores são elementos fundamentais numa sociedade em constante evolução. A eles cabe uma parte importante da formação das novas gerações. É uma profissão de grande responsabilidade onde as vertentes de formação humana, científica e pedagógica se interligam. A formação destes profissionais tem vindo a ser cada vez mais refletida e valorizada. $O$ ano de estágio, aquele em que pela primeira vez os alunos representam o papel de professores pondo em prática os conhecimentos adquiridos na Universidade, tem vindo a ser motivo de destaque. É um momento especial de formação, é o momento da prática em contexto real. Aos Supervisores, compete integrar estes grupos de formação no ambiente educativo e fornecer toda a informação necessária e disponível para aprenderem a ensinar. Esta aprendizagem não se resume apenas a saber planificar os conteúdos ou aplicar as mais recentes estratégias pedagógicas, implica também saber estar e viver numa comunidade educativa onde é fundamental uma boa relação com todos os outros, um clima de partilha e entreajuda, capacidade de promoção $e$ realização de atividades culturais, conhecimentos da orgânica administrativa e da legislação e uma aposta na formação contínua.

Este artigo apresenta um roteiro para o ano de estágio, testado com êxito, que pode servir de suporte ao Supervisor Pedagógico de qualquer escola na organização/planificação do ano escolar com os seus estagiários. $O$ conjunto de temas e atividades apresentadas permitem uma adequação aos vários tipos de contextos escolares. A sequência cronológica apresentada é aquela que habitualmente acontece durante um ano escolar. Enfatiza-se a progressão $e$ evolução da prática pedagógica, ao mesmo tempo que se realça a importância do acolhimento, do clima de escola, das relações interpessoais e da formação contínua. Propõe-se também um conjunto
\end{abstract}

\footnotetext{
${ }^{1}$ Este artigo é parte integrante, revista, do Relatório Reflexivo para obtenção do Mestrado em Ciências da Educação.

${ }^{2}$ Mestre em Ciências da Educação. Universidade Católica Portuguesa. E-mail: mgorettivalente@hotmail.com

${ }_{3}^{3}$ Doutorado em Ciências da Educação; docente na Universidade Católica Portuguesa. E-mail: jab2437@gmail.com
} 
de temas diversificados que permitem alargar os conhecimentos dos professores dotando-os de capacidades para o desempenho de várias funções.

Palavras-Chave : Supervisão, estágio, formação de professores.

\title{
INITIAL TRAINING OF TEACHERS. A ROADMAP FOR THE TRAINING YEAR
}

\begin{abstract}
Teachers are the key elements in a constantly-changing society. They are an important factor in the education of the new generations. It is a profession of great responsibility where the human, scientific and pedagogical components belong together, where the training of these professionals is being given more and more value and thought. The year of training, to which has been given special emphasis, is the one when the students, for the first time, play the role of teachers, applying all the knowledge they have acquired in the university. It is a special moment in their education, a moment when they acquire all the necessary and available information to learn how to teach and it is the supervisors' duty to integrate these training groups in the educational environment to help them with this task.

This learning is not simply to know how to plan lessons or to apply the latest pedagogical strategies. It also requires some attitude to live in an educational community where it is important to get on well with others, in an atmosphere of sharing, mutual help, ability to promote and carry out cultural activities. It is also important to provide them with some knowledge of administrative organization, legislation and a rigorous commitment to continuous training.

This article presents a guide to the training year, successfully tested, which can be used as a basis by the Pedagogical Supervisor of any school, together with his/her trainees, in the organization and planning of the school year.

The set of topics and activities presented make it possible the adjustment to the different types of school contexts. The chronological sequence presented is the one that usually occurs throughout a school year. The evolution of progression and pedagogical praxis are enhanced together with the importance of the school atmosphere, of the interpersonal relationships and continuous training. A variety of topics, enabling teachers to enlarge their knowledge and empowering them with the necessary skills to perform different tasks are also suggested.
\end{abstract}

Key Words: Supervision, training, teacher training

\section{INTRODUÇÃO}

A Educação tem vindo a ser basilar na formação das novas gerações, aquelas que acreditamos quererem construir uma sociedade próspera, 
honesta, justa e responsável. A escola é o local de eleição para a aquisição de novos conhecimentos e os professores são os grandes responsáveis pela sua evolução. Mas a promoção dos saberes também é da responsabilidade da comunidade e da família. O professor tem um papel de relevo, por isso é com frequência motivo de críticas ou elogios quando se trata de abordar o tema do ensino. É uma atividade profissional desempenhada por especialistas que obtiveram formação adequada para a desempenhar durante um período de tempo alargado, quer a nível científico quer a nível prático. Apostar, então, numa boa formação destes profissionais é contribuir para a melhoria da qualidade do ensino. A formação inicial de professores é o tema central deste artigo, destacandose o ano de estágio, como sendo aquele em que há um contacto direto com a realidade educativa e onde se podem experimentar e observar a validade ou não dos conceitos teórico/ científicos apreendidos na Universidade. Muitos investigadores consideram este momento de formação como sendo o mais produtivo e o mais marcante, pois determina e oferece a aquisição de um conjunto de competências essenciais a todo um percurso profissional com êxito. A curiosidade, alegria, entusiasmo e criatividade dos estagiários numa escola é contagiante por isso são, efetivamente, uma mais-valia para a escola e sobretudo para aqueles que com eles convivem e partilham saberes e experiências. O Supervisor/ orientador funciona como o andaime que vai permitir de uma forma organizada e coerente, em contexto real, a preparação para o desempenho profissional da arte de ensinar. Um ano de estágio é um tempo adequado à constatação de toda a orgânica escolar de uma forma generalizada. No entanto, há que ter em conta a especificidade de cada escola, de cada região e de cada comunidade educativa.

Um roteiro para o ano de estágio é sempre uma proposta pertinente, que em muito pode ajudar o supervisor/ orientador na planificação do ano escolar do estágio, e, sobretudo, quando desempenha esta função pela primeira vez.

\section{O AMBIENTE EDUCATIVO}

A Educação acompanha a evolução da sociedade, por isso assistimos com alguma frequência a reformas educativas muito significativas, quer a nível nacional, quer a nível internacional, de acordo com as mudanças políticas, sociais e económicas que se vão observando.

António Nóvoa (2007), na comunicação intitulada $O$ regresso dos professores, refere que as aprendizagens e os resultados destas têm sido a grande preocupação das políticas educativas deste século, logo, a 
capacidade do professor para promover essas aprendizagens está a ser intensamente refletida e avaliada. Por isso constata que os professores regressam à ribalta, por serem considerados os grandes responsáveis pelas aprendizagens e os resultados destas. Relembra ainda o autor que durante quase 40 anos as preocupações do ensino estiveram direcionadas para outras áreas que não as aprendizagens. A racionalização do ensino, a pedagogia por objetivos e o esforço para prever, planificar e controlar, preencheram os anos 80. Reformas nas estruturas dos sistemas escolares sobretudo a nível do currículo foram a preocupação dos anos 80. As organizações escolares, seu funcionamento, administração e gestão foram nos anos 90 o tema central.

\section{A ESCOLA}

A escola é, desde há muito, o local por excelência da realização de aprendizagens. É um espaço organizado, com pessoas especializadas na promoção do saber e onde os jovens devem complementar a sua formação básica, a sua escolaridade obrigatória. Com a entrada de Portugal na União Europeia verificou-se algum desfasamento formativo entre os jovens dos outros países e os portugueses. Esta situação modificou algumas políticas educativas que decretaram a obrigatoriedade da escolarização por um número variável de anos, primeiro de quatro, depois seis, oito e posteriormente nove e com a lei no85/2009 de 27 de Agosto, a escolaridade obrigatória passou a ser de 12 anos.

Posteriormente o decreto - lei $\mathrm{n}^{\circ} 176 / 2012$ vem reforçar a lei $\mathrm{n}^{\circ}$ 85/2009 e juntar um conjunto de informações pertinentes referentes à orgânica e aos elementos envolvidos neste contexto formativo.

Como pode verificar-se pelo texto alargado e esclarecedor deste decreto-lei, a formação dos jovens em idade escolar é um dever do Estado, pois contribui para um desenvolvimento social, económico e cultural da população em geral. Responsabilizar também a família pela educação dos jovens é congregar esforços em ordem a um mesmo objetivo.

A consulta de um dicionário é sempre eficaz para melhor se compreender um conceito ou o verdadeiro significado de uma palavra. Procurando o significado da palavra "escola" no Dicionário da Língua Portuguesa Contemporânea, da Academia das Ciências de Lisboa (2001:1497) obtivemos o seguinte: " instituição pública ou privada que tem por função ensinar, coletivamente, matérias de caracter geral ou especializado". Esta definição vem, de algum modo, confirmar a ideia generalizada da sociedade em que vivemos, de que a escola é o local ideal para se promoverem aprendizagens diferenciadas e os professores são os verdadeiros responsáveis pela aquisição dos saberes. Ora, os saberes que 
uma criança ou um jovem vai adquirindo durante a idade escolar também são da responsabilidade da família e da sociedade envolvente, por isso o decreto referido anteriormente realça este aspeto. A ligação ou parceria entre estes três grupos é muito importante no que respeita à divisão de responsabilidades. Cada um tem um papel fulcral na formação das novas gerações, por isso devem desenvolver projetos em conjunto. A escola de hoje tem uma participação mais ativa dos pais e encarregados de educação e ainda de outros organismos formativos que fazem parte da comunidade envolvente.

\section{O PROFESSOR}

Para a sociedade portuguesa a palavra professor tem vindo a ocupar um lugar de destaque, sobretudo quando relacionada com o tema Educação. A ligeireza com que muitas vezes é utilizada nos mais variados contextos, educativos ou não, banaliza a dignidade da profissão que representa. Uma pequena pesquisa, num dicionário de Língua Portuguesa, sobre o significado desta palavra, torna-se pertinente e servirá de alavanca para o tema que queremos abordar: o professor - quem é e o que faz.

Assim, a palavra professor, de origem latina - como a maior parte das palavras portuguesas - significa, de acordo com o Dicionário de Língua Portuguesa Contemporânea da Academia das Ciências (2001) “ pessoa que ensina uma disciplina, uma arte, uma técnica ou outros conhecimentos". O verbo que refere a ação desenvolvida por esta pessoa é ensinar, caraterística principal do professor.

O mesmo dicionário refere ainda como equivalentes as palavras: docente, formador e instrutor, o que pode fazer parecer que todos nós somos professores, uma vez que, sempre que partilhamos os nossos conhecimentos com os outros, sobre os mais diversos temas e em distintas ocasiões, estamos a promover o saber e a produzir conhecimento nos outros. Na verdade, saber ensinar e o que ensinar é uma área concreta da formação de professores, porque o ponto fulcral da sua atividade profissional.

Um professor é, antes de mais, um ser humano que vive em sociedade, tem sentimentos e merece todo o respeito do mundo. A atribuição de um conjunto diversificado de definições compreende-se pela quantidade de funções que muitas vezes tem de desempenhar. Reconhecer tão elevado número de competências é motivo de gáudio, mas, ao mesmo tempo, de consciencialização da necessidade de formação constante, de forma a darse resposta, de uma forma responsável, aos desafios que entretanto se coloquem. 
O professor está ligado ao conceito de escola e tudo o que a envolve. Na opinião de Day (2001) a eficácia da sua atividade está dependente do seu desenvolvimento profissional contínuo, umas vezes resultante da experiência ao longo da carreira, outras da planificação de uma formação mais especializada. O desenvolvimento profissional é importante para manter ou melhorar a qualidade dos professores e, naturalmente, a qualidade das escolas e do ensino.

Lieberman (1996:187) - citada por (Day:18) identifica três cenários em que o desenvolvimento profissional ocorre enquanto aprendizagens:

a) Instrução direta - através por exemplo da participação em conferências, realização de cursos, ateliês, ou meras consultas.

b) Aprendizagem na escola - através do treino de pares, de amizades críticas (o amigo critico), revisão e avaliação de procedimentos, investigação-ação, trabalhos de grupo e avaliação de portefólios.

c) Aprendizagem fora da escola - através de redes de trabalho, parcerias com outras instituições de ensino (universidade) e grupos informais.

Para complementar estas situações de aprendizagem o autor realça ainda a -Aprendizagem na sala de aula - através das reações dos alunos.

Empenhar-se num desenvolvimento profissional contínuo é uma atitude corajosa que revela um sentido de responsabilidade, competência e dedicação muito grandes. Day (2001:23) classifica-a de profissionalismo, ao mesmo tempo que refere que «a forma como os professores reagem enquanto profissionais é fundamental para a qualidade do ensino e da aprendizagem na sala de aula». A diversidade de funções, a intensificação do trabalho, as reformas consecutivas, são fatores importantes que podem dificultar a frequência de formação, por falta de tempo e energia. No seguimento desta constatação é ainda Day (2001:30) que nos coloca uma reflexão atenta sobre a ideia de profissionalismo, quando refere que os padrões de desempenho são impostos externamente, as competências são o centro dos modelos de formação (inicial ou contínua) e são introduzidos de novo os sistemas de créditos. Estas situações retiram autonomia aos professores para orientarem a sua carreira em função das suas necessidades, das suas aptidões e gostos, tendo sempre em conta a melhoria da qualidade do seu ensino e passam a cumprir normas, provenientes na maior parte das vezes dos relatórios internacionais, dos avanços das novas tecnologias, que competem com o saber científico do professor, e dos resultados da economia mundial.

O desenvolvimento profissional dos professores deve ser contínuo, sempre que estes tenham necessidade de ajustarem os seus conhecimentos 
a novas realidades escolares ou reformas educativas. Esta vontade em aprender mais, melhorar e diversificar os conhecimentos é uma maisvalia para a qualidade do ensino e da escola. Esta forma de pensar e atuar está condicionada e convive com outros aspetos importantes que investigadores e estudiosos da área da educação apelidam de " fases do desenvolvimento da carreira dos professores". A carreira profissional dos professores tem várias etapas e várias fases. Com base num esquema apresentado por Huberman (1995) - citado por Day (2001:101) verificamos que as fases estão relacionadas com o tempo de serviço e explicam-se da seguinte forma:

Entrada na carreira - momento de descoberta e sobrevivência.

$$
\begin{aligned}
& >\quad 1^{\text {a }} \text { fase - } 1 \text { a } 3 \text { anos - Estabilização } \\
& >\quad 2^{\mathrm{a}} \text { fase - 4 a } 6 \text { anos - Experimentação e Questionamento } \\
& >\quad 3^{\mathrm{a}} \text { fase - } 7 \text { a } 18 \text { anos - Diversificação e Questionamento } \\
& >\quad 4^{\mathrm{a}} \text { fase - } 19 \text { a } 30 \text { anos - Serenidade e Conservantismo } \\
& >\quad 5^{\mathrm{a}} \text { fase - } 31 \text { a } 40 \text { anos - Desinvestimento (sereno ou amargo) }
\end{aligned}
$$

A entrada na carreira é um período decisivo para os professores pois é o momento de consciencialização do que é esta profissão e de quais são as funções que tem que desempenhar, muitas vezes diferentes daquelas que imaginavam. As imagens construídas durante a formação vão-se alterando à medida que o contacto com a realidade se torna mais concreto e ativo. Há naturalmente uma reformulação de ideias entre as quais a procura de uma nova profissão.

Após o estágio, e nos três primeiros anos considerados o período da estabilização, os professores sentem-se com mais experiência, confiança e segurança para desempenharem as suas funções. Há uma consolidação e aperfeiçoamento das técnicas de ensino e uma melhor integração no grupo. É nesta fase que, de acordo com Cooper (1992:81), citado por Day (2001:105), a liderança deve reforçar o apoio aos professores, estimulando-os, envolvendo-os em novos projetos e novos desafios.

As fases seguintes dedicam maior atenção à progressão na carreira, à cultura de escola. É também frequente que nesta altura os professores procurem novos desafios, novas responsabilidades e até mesmo mudança de escola. As responsabilidades fora da escola começam a aumentar sobretudo com a família. O tempo dedicado á profissão começa a ser menor apesar do volume das tarefas aumentar. Na opinião de Vonk, (1989), citado por Day: (2001:106), esta fase pode levar a um reforço de energias, sobretudo na sala de aula devido a uma experiência já vivenciada e analisada. 
A $4^{\mathrm{a}}$ e a $5^{\mathrm{a}}$ fases são aquelas que Day considera as de «maior saber fazer no ensino». Há uma maior preocupação com o comportamento, empenho e valores dos alunos, pois já se verificou um grande investimento nestas áreas. Há os que calmamente aguardam a aposentação e os que se sentem estranhos dentro da sua própria escola, porque $\mathrm{o}$ ambiente mudou.

O desenvolvimento profissional de um professor deve ser sempre analisado tendo em conta o desenvolvimento pessoal de qualquer ser humano, e as características próprias de cada um. No momento atual, em que se observa uma reformulação grande a nível da organização e administração escolar, por causa da diminuição de alunos e das dificuldades económicas do país, podemos deduzir que as fases da carreira do professor anteriormente apresentadas, poderão ser alteradas ou mesmo nem se verificar.

\section{A FORMAÇÃO INICIAL}

A formação inicial de professores é considerada por muitos como a primeira etapa de um longo percurso de formação constante na área do ensino, de acordo com o tipo de alunos e de escolas onde o professor vai estar ao serviço da Educação. Esta primeira etapa, hoje de cerca de cinco anos, começa com a escolha de um curso superior direcionado ao ensino e, consequentemente, a sua frequência e aproveitamento a nível dos conhecimentos científicos, pedagógicos e práticos. Campos (2002) corrobora esta ideia quando diz que, em Portugal, a formação inicial de professores privilegia dois modelos: o académico, onde se adquirem conhecimentos científicos, didáticos e pedagógicos, nas instituições de ensino superior, de acordo com o currículo estipulado; e o técnico, onde se privilegia a parte do saber fazer, da prática em contexto de sala de aula, que se treina, apreende e analisa, numa escola cooperante da instituição de ensino superior, aquela onde os estudantes/professores realizam o seu estágio profissional. É, sobretudo, sobre este ano de estágio que vai incidir a nossa análise e reflexão, uma vez que foi um momento marcante da minha carreira como professora, porque aprendi muito relativamente às questões humanas e, naturalmente, também às pedagógicas. A responsabilidade da formação prática dos estagiários exigia uma reflexão e atualização constante das estratégias escolhidas e utilizadas. Por outro lado, a integração dos estagiários num ambiente novo, porque observado numa outra perspetiva e dimensão, permitiu reforçar a ideia do quão importantes são as relações humanas e os ambientes de trabalho, para que os objetivos sejam alcançados com êxito. Deste modo, a fase do acolhimento tornou-se um momento único nesta etapa de formação, à qual dedicamos mais e maior atenção, porque especial, para quem está a 
começar uma atividade onde a formação humana tem um papel de destaque. Estrela (2002) considera a formação inicial como um momento de preparação e desenvolvimento da pessoa em ordem ao desempenho de uma atividade. Ora, neste sentido, esta preparação e desenvolvimento da pessoa, deve também destacar a importância das atitudes e dos comportamentos por serem elementos básicos num ambiente educativo, onde se encontram jovens muito atentos aos exemplos e formas de agir do professor, porque são, na maior parte das vezes, modelos e linhas de orientação. A este propósito, Postic (1995:23) refere que «uma formação de professores deve provocar a evolução de atitudes e de comportamentos...» e justifica esta opinião, quando refere que «a criança, o pré- adolescente, tem uma necessidade fundamental de proteção, de apoio, no desenvolvimento do seu EU. Apoia-se nos professores, não apenas porque os vê como figuras paternais diferentes, mas porque sente a importância do conhecimento, o papel construtivo do funcionamento intelectual no seu desenvolvimento.»

A importância do professor na formação geral de um aluno é, desde há muito, reconhecida por todos, daí o facto de desempenhar uma quantidade considerável de funções na comunidade educativa, conforme as características do meio em que está inserido e dos objetivos da escola. Os desafios são muitos, por isso, na sua formação inicial, há necessidade de os dotar com competências diversificadas que vão atualizando numa formação contínua posterior.

As mudanças em Educação são frequentes, por isso os seus atores (professores) têm de estar preparados para as novidades e disponíveis para fazer formação. Estas mudanças são, segundo Azevedo (2001), resultantes das políticas educativas dos vários governos que pretendem, essencialmente, melhorar a qualidade do ensino, sobretudo nas escolas públicas, aquelas que o Estado dirige e controla mais diretamente. No entanto, o mesmo autor refere que as constantes mudanças podem produzir o efeito contrário, sobretudo se tivermos em conta que as escolas não são iguais em todo o país, porque instaladas em contextos diferentes, e que por isso a aplicação de regras generalizadas podem não produzir o efeito pretendido. Deste modo, o autor acredita que mais autonomia para as escolas, no sentido de adequarem as mudanças às características de cada escola, pode ser uma atitude mais prudente para a melhoria. Muitas das mudanças têm como base resultados estatísticos de inquéritos nacionais e internacionais, onde se destacam o abandono escolar ou a retenção dos alunos, situações que as políticas educativas pretendem resolver. A proposta de Azevedo, na sua obra Liberdade e Política Pública de Educação (2011) é, pois, que se faça uma melhoria gradual 
com a participação de todos, respeitando as características de cada meio educativo. Uma responsabilidade social pela educação pode e deve ser a direção da Educação. (p:117)

Os estagiários devem, pois, ser informados de que o ensino, tal como qualquer sociedade, está em constante mudança, por isso, devem estar preparados e disponíveis para ajustarem a sua formação e conhecimentos, orientados para a melhoria da qualidade do ensino e das aprendizagens. A formação contínua e o desenvolvimento profissional são realidades a considerar e a interiorizar. Qualquer uma das situações contribui para um crescimento humano e profissional. Formosinho (2009) entende que estas duas situações têm perspetivas diferentes. A formação contínua perspetiva o ensino e a formação e o desenvolvimento profissional, a aprendizagem e o crescimento.

$\mathrm{O}$ ano de estágio visa essencialmente preparar profissionalmente estes alunos/professores, por isso considera-se que uma abordagem clara e objetiva de todos os temas inerentes à profissão devem ser objeto de reflexão. Esta atitude formativa pode permitir, atempadamente, a escolha de um trajeto profissional diferente para aqueles alunos/professores que constatam haver um desfasamento entre o que pensavam ser a profissão de professor e aquilo que realmente ela é ou pode vir a ser. $\mathrm{O}$ ensino precisa de ter profissionais competentes, porque é uma profissão muito especial e de muita responsabilidade. A base da competência de qualquer atividade profissional está muitas vezes relacionada com o gosto pelo que se faz, logo, para se ser um bom professor também é preciso gostar de o ser.

\section{O ESTÁGIO E O ESTAGIÁRIO}

O ano de estágio é aquele em que os alunos fazem a sua formação em contexto de trabalho na escola e põem em prática os conhecimentos, sobretudo de pedagogia e didática, adquiridos durante os anos anteriores, com a ajuda de um professor cooperante, o orientador. É um ano muito importante porque tudo é novidade e é grande a apetência para aprender a ser professor.

O que fazem os estagiários durante um ano na escola? Poderia ser uma pergunta pertinente se não tivéssemos o conhecimento do funcionamento deste ano de prática, quer porque também já realizámos a nossa profissionalização, quer porque observámos a profissionalização de outros, ou, basicamente, porque participámos como orientadores na formação dos novos professores. Para um leigo, um ano é muito tempo para aprender a ensinar, porque parece que é apenas isso que se pensa que se aprende no estágio. Aprender a ensinar e aprender a ensinar a aprender mobiliza um conjunto de conhecimentos de áreas diversificadas que, 
interligadas, podem atingir objetivos muito positivos. As áreas da Pedagogia e da Didática são as que mais se evidenciam, outras há que se podem conjugar como por exemplo: informática, saúde, artes, etc.

Preparar profissionais capazes de corresponder aos constantes desafios da sociedade, é uma necessidade inequívoca e o principal objetivo do ano de estágio, pois sabemos que a qualidade da educação também depende em grande parte da formação/preparação dos seus professores. Neste ano de estágio os alunos/professores reúnem um conjunto de caraterísticas que podem contribuir e ser uma mais-valia para uma formação eficaz, onde podemos realçar a idade, a capacidade de absorção e a disposição para tal, a curiosidade, o empenho e a vontade de fazer mais e melhor, os sonhos que estimulam e agitam a criatividade e a responsabilidade pela imagem. É neste ambiente, tendo em conta todas estas caraterísticas e diversidades, que o orientador desenvolve a sua função de formador e os vai preparar ativamente para o desempenho do papel de professor, não só enquanto especialista em técnicas e métodos pedagógicos, mas também como responsável pela formação académica e humana dos jovens em idade escolar. É nestas escolas cooperantes que os estagiários se confrontam na realidade e pela primeira vez com o conceito de profissionalidade. Para melhor resumir o momento do estágio regista-se um excerto do despacho $\mathrm{n}^{\circ}$ 8322/011, de 16 de Junho que diz o seguinte:

"O novo sistema de atribuição de qualificação profissional para a docência
dá especial valor à área de iniciação à prática profissional consagrando à
prática de ensino supervisionada, como o momento privilegiado e
insubstituível, de aplicação dos conhecimentos, capacidades, competências
e atitudes ao contexto real das situações concretas da sala de aula, da escola
e da comunidade escolar."

A perceção concreta da realidade escolar e a forma como se deve e pode agir, perante dificuldades de caráter educativo ou relacional, devem ser abordagens graduais e feitas com calma e tranquilidade. Formar para a atividade docente implica também desenvolver, promover, despertar e valorizar a sensibilidade humana, porque toda a atividade profissional se vai desenrolar num ambiente onde o ser humano é imprescindível e está no centro das atenções. Um bom ambiente relacional é fundamental para a realização das aprendizagens, para o êxito e para a progressão de todos.

Day (2001) refere que os professores não se limitam a ser promotores do conhecimento, são também conselheiros das aprendizagens e nada nem ninguém tem um papel tão preponderante nessas aprendizagens, porque a relação pessoal professor/aluno é fulcral em pedagogia. Do mesmo modo, as aprendizagens feitas pelos estagiários serão também 
mais eficazes se houver um bom relacionamento entre o grupo de estágio e o orientador.

Uma das primeiras reações manifestadas pelos estagiários, quando em contacto com a realidade escolar, é a surpresa da diversidade de funções que poderão ter que desempenhar, apesar de já terem lido muitos estudos sobre as funções do professor. Num primeiro momento sentem-se inseguros e preocupados, mas com o decorrer da integração no ambiente escolar, este sentimento vai dando lugar a uma atitude positiva. A necessidade de formação constante e diversificada, começa a fazer parte dos seus projetos de formação contínua.

Estrela (2002) considera a formação inicial de professores o momento de «preparação e desenvolvimento da pessoa», por isso entende que se deve proporcionar aos professores em formação métodos, técnicas científicas e pedagógicas básicas, sem esquecer alguma formação pessoal e social.

Nóvoa (2007), depois de constatar que, de há uns tempos a esta parte, a comunidade de formação de professores, - e entende como pertencente a esta comunidade os departamentos universitários na área da Educação, especialistas internacionais e a indústria do ensino -, aumentou consideravelmente, o que, de certa forma, também proporcionou uma «inflação discursiva» (p:24) sobre os professores. O autor sugere então algumas medidas de atuação para ajudar a ultrapassar algumas situações menos confortáveis, onde destacamos a ideia de que a formação dos professores deve ser feita dentro da profissão, isto é, que é muito importante uma maior integração no contexto escolar e realizada logo nos primeiros anos de formação, tal como a estrutura da formação dos médicos. Um maior contacto com a realidade e a partilha de saberes com os seus pares promove uma melhor formação. Mais prática, mais reflexão e menos teoria.

\section{O ROTEIRO}

A escolha da palavra "roteiro" para caraterizar este capítulo, onde se faz uma proposta de atividades e temas a abordar e planificar com os estagiários, permite considerar que se trata apenas da indicação de um conjunto de ideias, já experimentadas, que podem resultar bem em contextos pedagógico-formativos. É uma das "rotas" a considerar na viagem de um ano de orientação. De acordo com o Dicionário da Língua Portuguesa Contemporânea da Academia das Ciências de Lisboa (2001:pág.3282) rota, é um vocábulo proveniente do francês antigo rote, hoje route, que traduzido quer dizer direção ou rumo.

O Roteiro do Ano de Estágio que aqui se propõe permite realçar 3 momentos basilares: o acolhimento e integração, a planificação e a prática 
/ treino. Para cada um destes momentos projetam-se atividades e temas diversificados.

Cada grupo de formação, isto é, cada ano de estágio, apesar das linhas gerais de orientação, que se traduzem muitas vezes por aprender $a$ ensinar, é um grupo único, porque tem características próprias. Deste modo, entende-se que a planificação das atividades e dos projetos devem ser elaborados em conjunto, com o contributo e reflexão de todos, depois de um melhor conhecimento das caraterísticas de cada um.

Preparação - Universidade - julho

- Escolha da escola

- Organização do grupo

- Comunicação à escola do nome e número de estagiários

\section{$1^{\mathrm{a}}$ Fase (setembro) $-\mathbf{1}^{\mathrm{o}}$ Período}

\section{Acolhimento/integração na escola}

Os estagiários conhecem a escola, o orientador, os colegas e tomam consciência das caraterísticas do meio escolar. O orientador conhece algumas das caraterísticas de cada um e em conjunto abordam a preparação do ano escolar. Participam nas reuniões gerais e de departamento e tomam conhecimento das turmas, dos horários e dos conteúdos a lecionar. Interagem com outros grupos de estágio da escola e começam a sentir-se enquadrados.

\section{$2^{\circ}$ Fase}

\section{Planificação e Observação}

- Em grupo planificam, de acordo com a programação do departamento, as atividades a desenvolver ao longo do ano bem como os conteúdos programáticos a lecionar, tendo em conta as caraterísticas da escola e dos alunos (planificação anual e por período). Tomam conhecimento das caraterísticas das turmas e dos alunos identificando os seus pontos fortes e fracos ou as suas necessidades educativas especiais.

- A observação das aulas e o registo da observação de cada uma delas permite refletir e explicar qualquer dúvida que, entretanto, surja. Todo o grupo assiste a todas as aulas do orientador.

- A reflexão e análise feita após a observação das aulas permite adquirir conhecimentos diferenciados e conhecer estratégias e formas de resolução novas ou, até agora, só conhecidas teoricamente.

- Uma participação ou intervenção pontual nas aulas, numa explicação de um conteúdo ou na ajuda a um aluno marca o primeiro passo da 
prática pedagógica, que vai aumentando à medida que o tempo vai passando.

-No final do $1^{\circ}$ período é frequente maior à-vontade nas aulas, melhor relacionamento com alunos e colegas, mais capacidade de reflexão sobre os conteúdos e estratégias e mais gosto e empenho pela atividade docente. Neste momento as intervenções nas aulas já são mais alargadas. É uma preparação gradual a uma prática independente.

\section{$3^{a}$ Fase $-2^{\circ} / 3^{\circ}$ Período}

\section{Prática pedagógica acompanhada}

Os alunos são distribuídos pelas turmas com quem sentem mais afinidade e começam a dedicar-se à preparação dos conteúdos a lecionar. Vão ganhando mais autonomia pois vão começando a lecionar uma aula e uma unidade.

- A preparação das aulas é feita em conjunto com a orientadora havendo sempre uma discussão prévia.

- A observação da aula é feita pela orientadora e pelos restantes elementos.

- Após a observação da aula, em conjunto, é feita uma reflexão/avaliação dos vários momentos da aula. Esta avaliação permite esclarecer dificuldades surgidas ou estratégias aplicadas ou a aplicar.

- A prática mais frequente vai permitir que no $3^{\circ}$ período haja uma maior autonomia capaz de assegurar a preparação e lecionação de uma unidade com qualidade.

\section{Atividades Paralelas}

Paralelamente à lecionação há um conjunto de atividades formativas ou culturais que têm que ser preparadas tais como:

- Visitas de estudo (escolha do local, pertinência do local a visitar, disciplinas envolvidas, preparação do itinerário, contacto com os transportes, informação aos encarregados de educação, informação às turmas, registo dos alunos, preparação da viagem com informações adicionais)

- Reuniões com Encarregados de Educação, de Departamento, de Conselhos de Turma, de avaliação (elaboração de convocatórias e de atas, organização dos dossiês, preenchimento de grelhas, registos de avaliação)

- Preparação das festas ou eventos (festividades do Natal ou Carnaval, dia da árvore, dia da poesia etc.)

- Concursos inerentes à disciplina (postais, contos, cartas, poemas) ou a nível nacional.

- Participação em formações propostas pela escola ou promoção e desenvolvimento das mesmas para a escola e comunidade. 


\section{Temas complementares}

Ao longo do ano, de acordo com as circunstâncias do momento, há temas pertinentes que podem e devem ser debatidos em grupo, pois complementam a formação do estagiário, como por exemplo:

- As relações interpessoais

- O clima de escola

- A organização da sala de aula e das aprendizagens

- A comunicação linguística

- Tipologia de aulas e estratégias de ensino

- A indisciplina

- O diretor de turma

- Organização e produção de materiais

- Técnicas e métodos de ensino

- Organização administrativa e diretiva da escola

- Legislação

- Ética Profissional

\section{CONCLUSÃO}

A formação inicial de professores é um tema sempre atual na agenda educativa e tem sido alvo de vários estudos e reflexões por se entender que estes são os grandes responsáveis pela melhoria das aprendizagens. Formar profissionais competentes e eficazes é o grande objetivo do ano de estágio que visa essencialmente proporcionar a prática pedagógica em contexto real. Nas escolas, estes grupos de alunos/professores testam e avaliam os conhecimentos teóricos adquiridos nas universidades. Cedo se apercebem que a teoria é diferente da prática. Pela mão sempre atenta do supervisor experimentam a arte de ensinar. Discutem, analisam, refletem, debatem e estudam todo um conjunto de realidades pedagógicas que lhes proporcionam a aquisição de conhecimentos diferenciados muito úteis para o desempenho desta atividade profissional. A prática pedagógica autorizada no ano de estágio é um momento fulcral e marcante para os novos professores. Tem que ser entendido com muita seriedade. $\mathrm{O}$ supervisor é um elemento fundamental porque é ele o grande responsável pela formação profissional destes professores. Durante um ano letivo tem a função de preparar em várias áreas os novos profissionais. O roteiro que aqui se propôs mostra bem a diversidade de tarefas e temas a abordar e pretende apenas servir de guia ou de suporte para aqueles que desempenham ou vão desempenhar esta função. 


\section{BIBLIOGRAFIA}

Azevedo, Joaquim (2011). Liberdade e Política Pública de Educação. Ensaio sobre um novo compromisso social pela educação. Vila Nova de Gaia: Fundação Manuel Leão.

Campos, B.P. (2002). Políticas de Formação de Professores de Ensino em Escolas Autónomas. Porto. Afrontamento.

Day, Christopher (2001). Desenvolvimento Profissional de Professores. Os desafios da aprendizagem permanente. Porto. Porto Editora.

Estrela, M.T. (2002).Relação Pedagógica, Disciplina e Indisciplina na Aula. Porto. Porto Editora.

Nóvoa, António (2007). "O Regresso dos Professores", in Conferência: Desenvolvimento profissional de professores para a qualidade $e$ para a equidade da Aprendizagem ao longo da Vida. Presidência Portuguesa do Conselho da União Europeia, Lisboa.

Postic, Marcel. (1995). Para uma Estratégia Pedagógica de Sucesso Escolar. Porto Editora.

\section{Legislação}

Lei $\mathrm{n}^{\circ} 85 / 2009$ de 27 de agosto

Despacho $n^{\circ} 8322 / 2011$ de 16 de junho 